\title{
EXPRESSÕES SOCIOESPACIAIS DA PANDEMIA DE CORONAVÍRUS (COVID-19): CONTRIBUIÇÕES GEOGRÁFICAS
}

\section{ARTIGO ORIGINAL}

SILVA, Marco Antonio Saraiva da ${ }^{1}$

BAGGIO, Ulysses da Cunha ${ }^{2}$

SILVA, Marco Antonio Saraiva da. BAGGIO, Ulysses da Cunha. Expressões socioespaciais da pandemia de coronavírus (COVID-19): Contribuições geográficas. Revista Científica Multidisciplinar Núcleo do Conhecimento. Ano 05, Ed. 07, Vol. 02, pp. 154-182. Julho de 2020. ISSN: 2448-0959, Link de acesso: https://www.nucleodoconhecimento.com.br/geografia/expressoessocioespaciais

\section{RESUMO}

O trabalho que ora se apresenta busca representar uma contribuição, pela ótica socioespacial, na abordagem da pandemia da COVID-19, um dos grandes problemas vividos nos tempos atuais. Trata-se de numa pesquisa essencialmente qualitativa, que se valeu de bibliografia selecionada e levantamentos de dados e informações em fontes variadas, permitindo-nos uma caracterização geral acerca da Geografia da Saúde e de sua importância no mundo atual. Nessa perspectiva, a análise se desdobra a um tratamento sucinto e processual das pandemias no mundo, com ênfase na da COVID-19, trazendo à tona aspectos considerados relevantes, desde a

\footnotetext{
${ }^{1}$ Graduação em Geografia pela Universidade Federal de Viçosa (2020).

2 Pós-Doutorado junto ao Programa de Pós-Graduação em Geografia Humana, da Universidade de São Paulo (2012-2013), Doutorado em Geografia (Geografia Humana) pela Universidade de São Paulo (2005), Mestrado em Geografia (Geografia Humana) pela Universidade de São Paulo (1995) e Graduação (Bacharelado e Licenciatura Plena) em Geografia pela Universidade de São Paulo (1991).
} 
origem do vírus até as suas repercussões nos diferentes espaços geográficos. Eles foram considerados enquanto instâncias territoriais submetidas às redes de fluxos e a lógica desigual de realização da globalização contemporânea. Nesse contexto abordaram-se tanto o papel de diferentes nações frente à economia global, quanto possíveis implicações de suas ações num mundo pós-pandemia. A abordagem empreendida procurou oferecer uma contribuição tanto a Geografia quanto a outros segmentos das ciências, sinalizando à necessidade de estudos mais sistêmicos e orgânicos em torno de temas de maior amplitude e complexidade, como é o caso da pandemia da COVID-19.

Palavras chave: Geografia da Saúde, COVID-19, pandemia, globalização contemporânea, desigualdade socioespacial.

\section{INTRODUÇÃO - NOTAS PRELIMINARES}

O trabalho que ora se apresenta busca representar uma contribuição, pela ótica socioespacial, na abordagem da pandemia da COVID-19, um dos grandes problemas vividos nos tempos atuais. Trata-se de numa pesquisa essencialmente qualitativa, que se valeu de bibliografia selecionada e levantamentos de dados e informações em fontes diversas disponíveis na internet. Ela se orientou a uma caracterização geral acerca da Geografia da Saúde, recobrindo um tratamento sucinto e processual das pandemias no mundo, com ênfase na da COVID-19, encetando uma problematização em torno da origem do vírus e, por fim, delineando um panorama comparativo da pandemia pelo mundo e no Brasil. O estudo realizado se põe em sintonia com preocupações em torno de um desenvolvimento maior na Geografia de uma Geografia da Saúde, no intuito de que essa empreitada possa se somar a outros esforços na compreensão do problema.

Nesse sentido, pode-se dizer que, de modo geral, quando algum tipo de evento põe em risco a segurança da sociedade, muitos ramos da ciência se mobilizam, de forma mais intensificada, para tentar entende-lo quanto as suas origens, causas e (ou) as suas possíveis consequências, tendo em vista a adoção de ações mais específicas à sua resolução. Esses esforços são de fundamental importância para alcançar formas 
eficazes de abordagem do problema, subsidiando, assim, a elaboração de soluções ou, ao menos, ações capazes de mitigá-lo. E a ciência, em verdade, se mostra como um dos poucos recursos mais ou menos seguro de que dispomos para resolver problemas e propor soluções. No entanto, é preciso considerar que a ciência, não necessariamente, seja capaz de produzir respostas óbvias, fechadas e seguras para todos os problemas que the são apresentados, o que também vale à área da saúde. É preciso, pois, ter clareza que a ciência não deve ser compreendida em si mesma, como uma variável isolada, mas sim como um conjunto de componentes, instituições e pessoas, que não são unívocas, monolíticas e evidentes.

Expondo uma enorme fragmentação e especialização do saber, a ciência recobre uma diversidade de profissionais, que produzem explicações para quase todos os acontecimentos ou problemas, as quais, não raro, acompanhadas de reducionismos, insuficiências analíticas e metodológicas.

No campo da saúde, mais especificamente, pode-se considerar ainda que abordagens demasiadamente fragmentárias possam perder de vista o paciente como ser humano em sua integralidade, considerando-se, nesse sentido, que a ideia de "cura" de doenças, envolve, geralmente, "uma complexa interação entre os aspectos físicos, psicológicos, sociais e ambientais da condição humana" (CAPRA, 1990, p.117).

E sob essa perspectiva, a ciência geográfica pode aportar contribuições relevantes aos estudos de questões e problemas da área da saúde, incluindo-se aqui o representado pela pandemia do coronavírus. Isso aponta para a importância, pra não dizer urgência, quanto a uma maior inserção e valorização da Geografia da Saúde em nossos ambientes científicos e educacionais, sobretudo nos espaços universitários.

É diante dessa preocupação e com esse propósito que o presente estudo se apresenta, oferecendo uma contribuição, entre outras, a uma abordagem socioespacial da pandemia da COVID-19. Mais especificamente o trabalho realizado também busca contribuir ao desenvolvimento de uma geografia da saúde renovada, que se coloque em fase com as condições socioespaciais da contemporaneidade. 
Tal perspectiva não se contenta com explorações marcadamente quantitativas de temas e problemas. Ela procura mobilizar dimensões outras relacionadas à esfera do vivido e da existência, das relações sociais e da vida cotidiana, em permanentes interações com o espaço e o meio ambiente. Todas elas sob a incidência de vetores de transição e impressionante ritmo de mudanças, que estabelecem a "imprevisibilidade do futuro" e certo predomínio da "visão da tragédia como destino inevitável e mau" (ABRANCHES, 2017, p.20-21).

Em meio a tantos avanços obtidos nas últimas décadas, experimentamos a convergência de acontecimentos das variadas instâncias sociais, econômicas, políticas, culturais, etc., e as dificuldades ao seu ajuste comportam o sentido de uma crise. Crise esta que, pela nossa compreensão, se redimensiona e se aprofunda com a pandemia da COVID-19.

À luz desses aspectos, oferecemos este estudo, com suas análises e reflexões.

\section{APONTAMENTOS EM TORNO DE UMA GEOGRAFIA DA SAÚDE}

Quando o planeta é acometido por terremotos, maremotos, vulcões e outros eventos que dizem respeito à dinâmica interna do planeta, entram em ação cientistas e estudiosos na sua abordagem, dentre eles geólogos e oceanógrafos, a fim de elucidar a questão e propor recomendações.

Do mesmo modo, quando surgem questões e problemas de caráter socioambiental no espaço terrestre entram em cena trabalhos da Biologia, Engenharia Ambiental, Sociologia, Direito e Geografia, entre outros segmentos, inclusive os citados anteriormente, haja vista a enorme amplitude e interdisciplinaridade da esfera ambiental. Contudo, dentre as mais variadas ciências existentes atualmente poucas possuem condições de análises tão abrangentes quanto a Geografia. Desde a sua gênese esse campo do conhecimento recebeu influências de variadas fontes do saber, passando a apresentar em seu objeto de análise, como nos esclarece o geógrafo Milton Santos (2006), o estudo das dinâmicas do espaço geográfico. 
Vivemos em um planeta em constantes transformações, sejam elas independentes da ação antrópica ou não. O que solicita constantes reavaliações acerca das causas e consequências desses processos, com o concurso de uma formação suficientemente sólida e atualizada à sua melhor aferição, acompanhando a dinamicidade dos eventos e seus contextos de ocorrência. Nessa perspectiva, o mesmo geógrafo, nos chama a atenção para especificidade dos tempos atuais, que ele identifica, com acuidade singular, como período "técnico-científico-informacional", que se desdobra em meio a uma "modernidade fluida".

A Geografia, mais especificamente, se devota essencialmente ao estudo das relações entre a sociedade na sua diversidade e a natureza; natureza esta progressivamente transformada pelas ações humanas, o que vale dizer pelo trabalho social historicamente realizado no espaço. Isso aponta para a unicidade da Geografia, dada pela inseparabilidade entre sociedade e natureza, ao mesmo tempo em que expõe a sociedade, em seu movimento diferencial, como o ponto de partida na abordagem de seu espectro de temas e problemas.

Conexões entre causas e consequências de um dado evento socioespacial pode estar sob a interferência de variáveis diversas, num mundo em que as relações se redimensionam e se potencializam pelo amplo intermédio de redes geográficas, especialmente de transportes e comunicações. As variáveis concernem à localização geográfica, condições socioambientais, econômicas, culturais e políticas, passando por aspectos mais específicos como matrizes produtivas dos territórios e sua inserção no mercado mundializado, bem como o recrudescimento da mobilidade espacial de populações, informação e mercadorias. Num mundo tornado globalizado e perpassado por redes, as relações estabelecidas entre pessoas e lugares colocam permanentemente a possibilidade de disseminação de vírus e bactérias. Em face da enorme conexidade e mobilidade geográfica de pessoas e fluxos de mercadorias, eles podem alastrar-se rapidamente pelo mundo, conformando cenários de pandemia.

Portanto, pode-se dizer que principalmente sob as condições do mundo globalizado contemporâneo a saúde das pessoas e a sua existência cotidiana assumem 
importância central, expondo-nos, assim, a relevância da Geografia no trato da questão.

É nessa perspectiva que a comunidade geográfica se volta ao fato que emergiu na China, em dezembro de 2019, quando o mundo inteiro passou a direciona-Ihe atenções devido ao surgimento de um vírus com alto potencial de transmissibilidade. Esse vírus é capaz de provocar complicações diversas à saúde humana, principalmente no aparelho respiratório, com consequências mais sérias, sobretudo em idosos e pessoas imunodeprimidas, tais como em transplantados, diabéticos, hipertensos, portadores de HIV e acometidos por câncer.

A proliferação e a agressividade do vírus chamaram a atenção de cientistas de muitos países. O que têm mobilizado grandes esforços de governos, instituições e profissionais da área da saúde em busca de repostas e soluções ao seu combate; problema que, no entanto, também se desdobra agudamente em outras esferas da vida social, como na economia, os quais, assim como no campo da saúde, desencadeiam efeitos em cascata. Vale ressaltar a enorme relevância dos profissionais, especialmente da área médica, que têm trabalhado arduamente para conter o avanço da Pandemia da COVID-19, atuando diuturnamente na criação de medicamentos e vacinas ao combate da doença, objetivando a sua cura, ou, ao menos, tentando colocá-la sob controle.

Hoje, com o mundo tomado pelo medo e incertezas, a ciência geográfica em muito pode também contribuir para o entendimento da situação. Com maior destaque no que afeta a um de seus seguimentos, o da Geografia da Saúde. Ele vale de estudos de vários outros campos, como Ciências Sociais, Sociologia, Estatística, Meio Ambiente, Biologia, Medicina e Epidemiologia. A Geografia nos permite compreender a dinâmica espacial da COVID-19 para além das formas mais comuns de transmissão (contato direto entre pessoas), pois estas possuem certas características e intensidades, a depender do local e do contexto da sociedade em que ocorrerem.

A Geografia da Saúde no Brasil, segundo Alievi e Pinese (2013), tem Josué de Castro, Carlos S. Lacaz e Samuel Pessoa como os primeiros a contribuir para o 
desenvolvimento desse campo de estudos no âmbito da ciência geográfica. Para Faria e Bortolozzi (2009), a concepção de espaço de Milton Santos[3] também contribui para a Geografia da Saúde brasileira, embora esse autor não estivesse vinculado de forma direta a pesquisas no campo da saúde, exceto em eventos pontuais de que participou. O geógrafo proporcionou, no entanto, subsídios valiosos à ciência epidemiológica, os quais, para além da categoria central de espaço, se desdobraram aos conceitos de território[4] e de meio técnico-científico-informacional[5]. Sendo também utilizados em abordagens pela economia, sociologia, urbanismo e outras áreas do saber social, estes conceitos se mostraram teórica e tecnicamente relevantes à análise e gestão de processos e situações de saúde-doença a partir de mudanças espaciais estruturais. Estas eram pensadas à luz do recrudescimento das relações sociais, sobretudo a partir dos anos 1970, com a ampliação e extensividade da urbanização e, de forma associada, da suburbanização e a expansão de periferias urbanas. Nesse sentido, Milton Santos compreendia as expressões do binômio representado pela saúde-doença como manifestações sociais, vendo-as, portanto, para além dos limites clínicos.

Segundo Alievi e Pinese (2013), é partir dos anos 1940 que os geógrafos passaram a atentar para questões que envolvessem saúde, doenças e organização espacial. Valendo-se do desenvolvimento teórico, técnico e epistemológico da própria Geografia, e também de outros campos do saber, a evolução da Geografia da Saúde permite compreender como um dado ordenamento espacial da sociedade (aqui considerados aspectos sociais e ambientais diversos) pode ser propício ao aparecimento de doenças. Acerca disso, pode-se exemplificar através de associações entre os impactos da industrialização, urbanização expansiva e a saúde humana, envolvendo efeitos do desmatamento, degradação de recursos naturais, proliferação de bolsões de pobreza e problemas sanitários relacionados. 


\section{PANDEMIAS: ASPECTOS GENÉTICOS E CARACTERIZAÇÃO GERAL}

O nosso planeta, a depender da escala e do objetivo do estudo, pode ser considerado tanto pertencente a um sistema quanto o próprio sistema. Destaque-se aqui que um fator não exclui o outro, dado que o universo é dinâmico. Por conseguinte, novas situações nos aparecem sem necessariamente apresentar uma linearidade cíclica temporal. Além do mais, o tempo cíclico escalonado é algo artificial, inventado pelo homem a fim de coordenar suas ações, tentando, a todo o momento, estar no controle de todas as situações.[6]

Nesse sentido, tudo que não esteja planejado ou até mesmo previsto é encarado com certo grau de estranhamento ou insegurança, justamente pela falta de controle sobre os possíveis desdobramentos dos eventos. Quanto a isso, talvez, uma das situações que mais põe em evidencia as fragilidades da humanidade em lidar com situações adversas são as doenças de aparecimento abrupto, com grande potencial de letalidade e com uma transmissão generalizada e quase incontrolável. E quando os contágios recobrem grandes dimensões espaciais do planeta, eles passam a ser considerados pandemias[7]. E a história da nossa civilização revela a ocorrência de diversos casos desse tipo, com variações de mortalidade que variam de milhares a milhões de pessoas.

Dentre as diversas pandemias registradas, a Peste Negra ou Peste Bubônica [8], como também ficou conhecida, assolou a Europa na segunda metade do século XIV, levando a óbito dezenas de milhões de vidas humanas.

Segundo (SAAVEDRA e DIAS, 2011, p.223) "a peste é essencialmente uma zoonose de roedores, causada pela bactéria Yersinia pestis, que pode infectar o homem quando este invade o seu ecossistema". Segundo os autores, a transmissão ocorre principalmente por picadas de pulgas que se proliferam através dos roedores, com destaque para os ratos. Na Idade Média a precariedade quanto às questões sanitárias era geral, não sendo um marcador socioespacial igual aos tempos atuais. Entretanto, sobretudo em espaços periféricos do sistema-mundo, especialmente nos bolsões de 
pobreza tomados por favelas e habitações autoconstruídas infra-normais, a incidência de condições sanitárias adversas é muito grande, empiricamente verificável.

Outra pandemia, que atingiu mortalidade de dezenas de milhões de indivíduos, foi a "Gripe Espanhola". Esta, diferentemente da Peste Negra, é uma doença de natureza virótica do tipo influenza A (H1-N1).

Ao contrário do que o adjetivo sugere essa gripe não é originária da Espanha, e acredita-se que tenha tido seus primeiros casos nos Estados Unidos da América do Norte. O que se tem é que o período do surgimento da doença (fim da $1^{\text {a }}$ Guerra Mundial) era crítico, conturbado e com pouca divulgação de notícias. Dentre os países que mantinham uma imprensa mais livre, a Espanha se destacava, e foi justamente esse país que apresentou ao mundo essa grande pandemia, que, popularmente, foi "batizada" de "gripe espanhola".

Podemos destacar, ainda, outras pandemias causadas pelo vírus influenza, que levaram a morte milhões de pessoas, como, por exemplo, "Gripe Asiática", com a variedade A(H2N2), em 1957; "Gripe de Hong Kong"- A (H3N2)- em 1968; e a "Gripe Suina"- A (H1N1) pdm 09- em 2009. Entre estas duas últimas datas, outras contaminações de menor abrangência, agora classificadas como epidemias, também causaram muitas baixas. Podemos destacar a "Gripe Russa" (1977); "Gripe Suína" (1976 e 1988); e Gripe Aviária (1997, 2003 e 2007).

Percebe-se, pelo exposto, que dentre as pandemias virais causadoras de complicações respiratórias e transmitidas entre pessoas, principalmente por gotículas aerógenas, o vírus influenza, com suas variações, é o grande protagonista.

No entanto, outro vírus, que oferece grande risco à saúde das pessoas, e que, por suas especificidades e consequências à saúde humana - ainda em estudo -, merece a devida atenção é o coronavírus. Ele faz parte de uma grande família de vírus responsável por causar infecções nas vias respiratórias, variando desde um simples resfriado às síndromes respiratórias. Segundo o Ministério da Saúde (2020), os primeiros coronavírus humanos foram isolados em 1937, mas somente em 1965 
recebeu tal designação em virtude do seu fenótipo ser similar ao de uma coroa, daí seu nome. Ainda de acordo com o Órgão, ao longo da vida a maioria das pessoas, hora ou outra, acabam por serem infectadas pelo tipo mais comum desse vírus (o Alpha coronavírus 229E e NL63 e o Beta coronavírus OC43, HKU1). Dentre os infectados, as crianças, por terem menor imunidade, são a maioria. Ressalta-se aqui que os idosos, transplantados, operados e diabéticos também apresentam imunidade reduzida, sofrendo, com maior freqüência, os ataques desses vírus. Desse modo, esses segmentos da população são os que oferecem os maiores riscos de desenvolverem complicações mais sérias provocadas por esse vírus.

Em 2012, um dos tipos de coronavírus denominado de MERS-CoV[9] foi detectado na Arábia Saudita (JESUS, 2016). O que se sabe até o momento é que o vírus tem procedência zoonótica[10], tendo como agente primário de transmissão os dromedários[11](JESUS, 2016). De acordo com a Organização Mundial da Saúde (OMS) não é possível afirmar com exatidão a origem do vírus, mas tudo indica que tenha vindo de morcegos em um passado remoto. Ainda segundo a OMS, desde 2012 foram relatados casos em pelo menos 27 países[12], dentre eles a China. Ressaltase aqui que a OMS credita $80 \%$ dos casos humanos relatados a Arábia Saudita.

Segundo a Organização Pan-Americana da Saúde (OPAS) no final de 2019 uma nova variedade do coronavírus foi identificada em Wuhan, na China. Até o momento essa variedade ainda não havia sido observada em humanos, situação que serve de agravante, uma vez que seu controle se torna mais dificultoso. Acerca disso, em janeiro de 2020 a China divulgou as primeiras mortes causadas pelo vírus, situação que serviu de estopim para desencadear reações no restante do mundo, que variaram desde suposições quanto à verdadeira origem da COVID-19, a críticas relacionadas ao protelamento na divulgação dos casos.

\section{EXPLORAÇÕES SOBRE A ORIGEM DA COVID-19}

Como já exposto, a cidade de Wuhan foi apontada como o centro dispersor da COVID19 para o mundo. Isso, no entanto, não significa dizer ou afirmar que tenha sido ali que o vírus tenha surgido, havendo ainda estudos e investigações em torno desse 
aspecto, não se tendo, até o momento, nenhuma conclusão definitiva sobre a questão. Quanto a isso, Escobar (2020) aponta que o vírus encontrado em Wuhan seria, segundo fontes científicas mencionadas, uma terceira mutação do patógeno, num total de cinco mutações principais, sendo que as duas primeiras teriam ocorrido fora do território chinês. A partir disso, levantou-se a hipótese, de acordo com Escobar, que o vírus teria surgido num laboratório de armas biológicas nos EUA. Esse vírus teria sido transmitido em Wuhan por um soldado americano que possivelmente teria visitado um mercado de animais silvestres, por ocasião de um evento esportivo militar internacional ocorrido nesta cidade em outubro de 2019.

Essa questão tem envolvido enorme controvérsia, em meio à profusão de informações falsas e duvidosas, num espectro de abordagens que envolvem desde recombinações genéticas naturais do vírus até a sua criação laboratorial, com propósitos estratégicos de poder.

Até onde se sabe, não existiria ainda um estudo conclusivo e comprobatório sobre a gênese do vírus. No entanto, a grande maioria das suspeitas recai sobre os Estados Unidos e a China, as duas maiores potencias econômicas mundiais, que disputam o controle da economia global.

Os que imputam à China a responsabilidade pela criação do vírus (boa parte americanos) refutam estudos científicos de países como Reino Unido, Austrália e o próprio Estados Unidos, que afirmam que o SARS-COV-2 não foi criado em laboratório, sendo uma variação natural da família dos vírus causadores de síndromes respiratórias agudas graves (SARS).

Os defensores de ideias conspiratórias argumentam que a pandemia interfere diretamente na circulação de pessoas, mercadorias e capital, repercutindo diretamente nas bolsas de valores, desvalorizando as ações de várias empresas, o que é um fato. E seria nesta situação que a China se beneficiaria, pois poderia comprar ações a preços reduzidos, para depois, tão logo a situação se normalizasse, obter margens elevadas de lucratividade, com a retomada de valorização desses títulos. Portanto, pode-se considerar que a pandemia envolve uma dimensão 
financeira estratégica ao plano dos interesses hegemônicos, com a China na linha de frente das operações.

Para endossar os argumentos dos que desconfiam dos chineses, coloca-se em pauta, a todo o momento, o fato da China não ter alertado o mundo, de forma prévia, sobre a situação de estarem sofrendo uma expressiva mortalidade decorrente de um agente "desconhecido". Outra suposição é que eles desenvolveram o patógeno para posteriormente apresentarem medicamentos e equipamentos[13] eficazes ao seu combate. Em relação a equipamentos, Landim (2020) observa que na primeira semana de abril de 2020, os respiradores, que eram negociados a custos médios de US $\$ 17$ mil, tiveram um acréscimo de $211 \%$ em menos de 7 dias. Essa enorme elevação nos preços pode ser explicada pela lei da oferta e demanda - um velho postulado da economia clássica criado por Adam Smith para explicar como se dá a dinâmica no mercado de compra e venda de mercadorias. Desse modo, tais produtos gerariam lucros exorbitantes ao país em face das expectativas da disseminação planetária do Sars-Cov-2.

Pelo lado dos Estados Unidos, Ihes são atribuídos a responsabilidade pela criação do vírus, ressaltando-se que os partidários dessa idéia também refutam estudos publicados que afirmam que o surgimento do Sars-Cov-2 se deu a partir de processos naturais, sendo, assim, um produto da seleção natural. Para estes, o vírus teria sido desenvolvido num laboratório biológico das Forças Armadas dos EUA, como já mencionado, na instalação de Fort Detrick, na cidade de Frederick, estado de Maryland.

Nessa linha de investigação, acredita-se que a chegada do vírus à Wuhan tenha se dado por intermédio daqueles soldados americanos, no contexto dos Jogos Militares Mundiais disputados nesta cidade. O evento ocorreu entre 18 e 27 de outubro de 2019, cuja delegação contou com 280 pessoas. As suspeitas surgiram depois que algumas pessoas dessa delegação foram hospitalizadas em Wuhan, com infecções respiratórias de causas desconhecidas. 
Pode-se considerar que ao plano dos que responsabilizam os Estados Unidos pelo vírus, o intuito seria o de promover a desestabilização entre os chineses, gerando crises de instabilidade econômica e fomentando preconceitos, como, aliás, se observa pelos ataques que eles vêm sofrendo em relação aos seus hábitos alimentares culturais.

Diante de tantas incertezas, emitir juízos de valor quanto a origem do vírus pode ser equivocado e até mesmo temerário. Todavia, considerações acerca dos papeis desempenhados pelos principais envolvidos no contexto geopolítico e econômico mundial, e as implicações desse evento para o restante do planeta, tornam-se bastante factíveis. Elas comportam o sentido de um recrudescimento ainda maior das contradições entre a política e a economia, entre a lógica do exercício do poder às escalas nacionais e a lógica econômica de um mundo globalizado.

Vale lembrar que os Estados Unidos se consolidaram como a grande potência mundial a partir do fim da Segunda Guerra (1945). Desde então, deu-se início a uma corrida desenfreada em busca de avanços tecnológicos que pudessem assegurar sua hegemonia em face do restante do mundo.

Durante esses tempos de supremacia econômica e tecnológica dos Estados Unidos, a população mundial passou por grandes transformações sociais. O que se mostrou como reflexo, em grande medida, de ações que objetivavam não só a manutenção de um padrão de consumo totalmente desigual dos norte-americanos em relação a outras sociedades do mundo, como também o domínio da economia o global. Para isso, uma nova lógica de apropriação do capital foi implantada, a neoliberal, que encontrou substrato ideal para sua disseminação nas malhas da globalização. O que se deu num contexto de emergência e desenvolvimento de um novo ciclo de crise da economia mundial, no qual o neoliberalismo encontrou terreno fértil à sua expansão, impulsionado por desregulamentações econômicas e forte desenvolvimento da ciência e da tecnologia, com destaque às dos setores associados de comunicação e informação. 
Sob a lógica de um novo padrão de acumulação do capital, de feição flexível e espoliativa (HARVEY, 1992; HARVEY, 2005), uma das principais características alcançadas por essa nova fase da globalização, marcadamente de égide financeira (CHESNAIS, 1996), diz respeito à velocidade da circulação de produtos, pessoas, valores e, principalmente, informações. Em grande medida é a informação que permite o desencadeamento de várias outras ações, que podem culminar em maior acúmulo de capital por corporações e conglomerados empresariais (PIKETTY, 2014); e, por extensão, de controle do mercado e do território. E não sem razão poder-se falar, acrescente-se, da formação de cidades e territórios corporativos, dada justamente pelo protagonismo desses agentes em sua constituição e funcionamento. Sobretudo em países periféricos, como o Brasil, essa condição socioespacial potencializa disparidades e restrições de acesso a bens fundamentais à reprodução social e à vida, dentre elas equipamentos e serviços de saúde, principalmente públicos.

Destaque-se aqui que a China, nos últimos tempos, vem despontando como grande potência no mercado mundial. Sua trajetória de desempenho, rumo à consolidação econômica, científico-tecnológica e militar iniciou-se, é importante dizê-lo, bem antes do que normalmente se diz, ou seja, já nos anos 1960, antes, portanto, da Revolução Cultural, de Mao Tsé-Tung.

Uma das ideias mais difundidas em relação à economia chinesa é que ela tenha despontando principalmente a partir dos anos 1980, o que não é bem a verdade. Herrera (2018) nos adverte quanto ao traço simplista e falacioso dessa narrativa, que distorce e obnubila fatos relevantes da situação chinesa e de seu ideal capitalista, que comporta o sentido de um projeto de tornar-se uma potência econômica. Segundo o autor, tal discurso simplificador oculta três realidades fundamentais em relação ao país: a primeira se refere à profundidade milenar da história; a segunda, quando o seu PIB ultrapassou 10\% de crescimento anual em 1980, o que se deu sob estruturas e instituições socialistas que ainda permaneciam em vigor; e a terceira diz respeito aos números significativos alcançados por sua economia antes mesmo da morte de Mao Tsé-Tung (1976). 
Quanto ao sistema capitalista chinês e seus resultados, Herrera (2018) assinala que ao analisar-se a taxa de acumulação de capital produtivo[14] do país, os números apontam 9,7\% para o período de 1952-1978 e 10,9\% de 1979-2015.

Diante disso, o que se busca aqui não é assumir uma posição pró ou contra o capitalismo, mas frisar que a China, há várias décadas, vem construindo o seu caminho para se tornar a maior potência do mundo. Não há como negar que o capitalismo e sua lógica produtiva tenham encontrado nesse país um terreno fértil à sua expansão, que se desdobra pelo mundo através da dispersão de sua cadeia produtiva e de seus negócios, transformando-se no maior exportador de mercadorias do planeta e num dos maiores importadores. Portanto, apresentando uma expressiva balança comercial positiva. A China, paradoxalmente, revela tanto evidências de um robusto desempenho econômico, científico-tecnológico e uma impressionante produção de seu espaço construído, como também de desrespeito a direitos humanos, exploração intensiva e ampliada de força de trabalho (envolvendo a adoção de práticas análogas à escravidão) e grandes problemas ambientais.

Possuidora de uma cultura milenar e diversificada e com uma população de aproximadamente 1,43 bilhões de pessoas (ONU, 2019), por enquanto o maior contingente populacional do planeta, atualmente a China possui o segundo maior PIB do mundo, com chances de assumir a primeira posição ainda na primeira metade desta década. Outro aspecto importante desse país diz respeito ao fato dele ser uma referência na produção industrial de aparelhos eletrônicos e seus derivados; praticamente toda a cadeia produtiva do planeta passa, direta ou indiretamente, por ele. Inegavelmente, a China possui um protagonismo bastante importante no cenário global, desde a rota da seda[15], encontrando-se numa acirrada e estratégica disputa com os Estados Unidos ao domínio hegemônico do mercado mundial.

Mundialmente conhecida pela grandiosidade, complexidade e sofisticação de suas estruturas construídas[16], a China expõe, nesse sentido, a presença de um meio técnico-científico-informacional expressivo em seu território, inclusive na região em que o vírus da COVID-19 teria surgido, expondo uma espécie de contradição intrigante. 
Os impactos da pandemia da COVID-19 na economia chinesa não são ainda muito bem conhecidos, podendo afetar sensivelmente diversos espaços do mundo, produzindo uma escala de danos que pode evoluir para uma recessão global. $\mathrm{Na}$ economia chinesa retrações expressivas podem ser constadas nos segmentos da indústria, vendas a varejo e ativos fixos, muito acima do esperado para os tempos atuais.

Esta sucinta abordagem relativa aos Estados Unidos e China buscou propiciar subsídios à questão da origem do vírus causador da pandemia da COVID-19.

\section{CENÁRIOS TERRITORIAIS DA CONTAMINAÇÃO DA COVID-19}

Como já advertimos, não é sensato, nesse momento, tecer considerações a respeito de responsáveis ou culpados pela doença - se é que existe "um" - que assola o mundo nesses tempos. Considerar que o capitalismo e o neoliberalismo, com suas contradições, respondam, grosso modo, pela pandemia da Covid-19, nos parece um exercício de miopia e simplificação em relação ao problema, comportando um traço fortemente ideológico. Tal visão desconsidera e faz uma espécie de tábula rasa de fatos históricos relativos a outras doenças e pandemias anteriores ao advento do capitalismo, como foi o caso, por exemplo, da Peste Negra.

Ademais, a Globalização, organicamente associada à lógica capitalista, demanda um olhar mais atento e criterioso antes de se fazer apontamentos no intuito de imputarIhe responsabilidades pela difusão do vírus Sars-Cov-2. Nessa direção, Yuval Harari (2020) assinala que o mundo globalizado, quando comparado a outros períodos da história, oferece melhores condições para a contenção dessa pandemia ou de outras calamidades que possam surgir. Ele corrobora seu argumento com o resgate[17] de alguns eventos catastróficos pretéritos, relacionados à saúde mundial.

Para Harari (2020), fechar o mundo, de forma drástica e generalizada, impedindo a circulação de pessoas e mercadorias, não é a melhor das escolhas. Isso, no entanto, não significa que o autor não aprove ou reconheça as medidas de segurança adotadas pelos países na tentativa de conter o avanço da pandemia. Pelo contrário, ele 
concorda que o isolamento social, temporário, é uma boa estratégia na luta contra a COVID-19, mas deixa bem claro que este procedimento deve ser feito nos moldes de um acordo global, de modo que médicos, cientistas, políticos, jornalistas e empresários possam circular sem maiores restrições.

Ao se referir às contribuições da Globalização na superação de dificuldades mundiais, Harari (2020) destaca a possibilidade de trocas de informações em tempo praticamente real. Quando forjadas em bases sólidas de ética e transparência, tendo como princípio o respeito à vida e a integridade do ser humano, as informações podem contribuir para salvar milhões de pessoas. E como o próprio autor salienta, uma situação vivida pela manhã, por um médico na Itália, pode ajudar outro à tarde no Irã, e assim sucessivamente. Além das trocas de informações, Harari (2020) também aponta os auxílios com recursos, tais como equipamentos e medicamentos que podem ser transferidos de um local para o outro para salvar o maior número possível de vidas.

É praticamente imponderável imaginar todas essas possibilidades sem a globalização. Se, por um lado, ela permite uma circulação mais acelerada das doenças contagiosas, através das redes geográficas de mobilidade material, por outro, também permite que soluções sejam tomadas numa velocidade nunca vista antes.

Isso não significa dizer que não se reconheça, na Globalização, as implicações do capitalismo e sua lógica de realização desigual e seletiva, inscrevendo-se, assim, de forma contraditória no espaço, insuflando desigualdades e conflitos. Desigualdades estas que histórica e estruturalmente se apresentam como um componente à própria reprodução e sustentação do capitalismo global. Contudo, é necessário analisar sob quais circunstâncias socioespaciais o vírus se difundiu e que expressões tal dispersão adquiriu, com suas implicações.

Não devemos, portanto, recair em certos simplismos, em grande medida veiculados por parcelas da imprensa, fazendo comparações, de modo isolado, da ação do vírus em alguns países, sem levar em devida consideração suas particularidades 
socioespaciais, tais como condições ambientais, estruturas territoriais, dinâmica da população, pirâmide etária, distribuição de renda, acesso a informações, etc.

Analisar isoladamente o número de casos da COVID-19 e fazer comparações entre os países como se todos apresentassem a mesma realidade é um grande equívoco. Por isso, as abordagens necessitam ser mais abrangentes, correlacionando o máximo de variáveis possível na busca de dados mais consistentes.

Dentre os aspectos a serem observados, a média de idade da população de cada país é um dado muito importante, haja vista que grande parte dos óbitos está relacionada a pessoas mais idosas, que estão sob riscos maiores. Segundo Desjardins (2019) a Europa é a região do mundo que apresenta a média etária mais alta, que é de 42 anos, seguida por América do Norte (35), Oceania (33), Ásia e América do Sul (31) e África (18).

Tais diferenças reverberam, entre outras coisas, na situação socioeconômica dos territórios. A África, salvo alguns casos[18], é o continente que abriga o maior número de países com baixo Índice de desenvolvimento Humano (IDH). Do mesmo modo, também é sabido que a Europa reúne boa parte dos países com os melhores IDHs do mundo.

O velho continente - berço da civilização ocidental, da Revolução Industrial e palco das duas grandes Guerras Mundiais - possui uma das mais importantes estruturas tecnológicas do mundo, com pólos diversificados e economias bem consolidadas. Além disso, a Europa também representa um dos destinos turísticos internacionais mais visitados do planeta, podendo-se destacar aqui a França, Espanha, Itália, entre outros. Esses aspectos explicam, em grande medida, a liderança mundial do continente no fluxo de pessoas.

Em relação a essas variáveis, vale lembrar que os Estados Unidos apresentam condições bastante similares às da Europa. Com uma enorme expressividade econômica e tecnológica, sendo o segundo maior pólo internacional de turismo do mundo, somado ao seu grande contingente populacional, colocam esse país, 
juntamente com alguns países da Europa - especialmente Itália - e a China, como territórios nucleares na rede geográfica da pandemia.

Outra questão que deve ser observada ao analisar os impactos da pandemia é o modo como cada nação enxerga a questão da saúde. Nesse sentido, cabe aqui uma pequena explanação a respeito das diferenças existentes entre alguns países. Para isso, levaremos em consideração alguns dos países mais desenvolvidos do mundo, com destaque aos integrantes do seleto grupo do G7.

Na Alemanha, o acesso ao sistema de saúde não é público e pode ser acessado de duas formas: o Seguro Estatal (Gesetzlicher Krankenversicherung); e o Seguro Privado (Privater Krankenversicherung). Diante disso, qualquer pessoa que resida nesse país é obrigada a ter um destes planos, que se diferenciam tanto no custo como na velocidade de atendimento, que é mais rápida no sistema privado. De todo modo, independente do modelo de sistema oferecido, a Alemanha tem sido uma das referências no combate à COVID-19. Os resultados apresentados pelo país durante a pandemia não se devem apenas às suas estruturas hospitalares, mas, também, a rápida ação dos governantes em decretar o isolamento social, tão logo o vírus fora identificado em seu território.

Outros dois integrantes do G7 que estão com bom desempenho na luta contra a COVID-19, são o Canadá e o Japão. Para os canadenses, o acesso a saúde se dá por hospitais privados, porém subsidiados pelo governo, que entende que toda a população tem direitos iguais a tratamentos de saúde. Vale ressaltar que o país é dividido em províncias, e que cada uma pode organizar de forma particular esse acesso. Mas, de forma geral, reitera-se, boa parte dos serviços são subsidiados pelo Estado.

Já no Japão, serviços referentes à saúde, segurança e coleta de lixo são oferecidos pelo governo. Diante disso, todos os residentes no país precisam aderir a um seguro de saúde governamental se quiserem ter acesso a esse setor. Os japoneses, além de muito disciplinados, possuem enorme capacidade de reação frente a situações catastróficas, tendo em seu histórico, como se sabe, duas bombas atômicas 
(Hiroshima e Nagasaki em 1945) e inúmeros abalos sísmicos, com destaque para o de 2011, causador de mortes e destruição na costa do país. Essas questões, somadas a outras, como recursos financeiros e isolamento social rigoroso, podem ser um dos motivos para que o Japão, com sua grande população e seu papel na economia global, esteja em melhor situação que os outros seis do Grupo ao qual pertence.

Para a França, Itália e Reino Unido o sistema de saúde é visto como uma responsabilidade do governo. Obviamente, isso não significa que todos possuem a mesma estrutura, pelo contrário, assim como no Canadá as diferenças existem mesmo dentro de cada país, os quais possuem particularidades nas divisões de suas federações.

No entanto, a visão que a população tem da saúde se mostra, de modo geral, um tanto que homogênea, conquanto esta envolva diferentes dimensões e variáveis; o que já não acontece tanto com a idéia de doença. $E$ isso em razão desta contar com um grande acervo de estudos e informações historicamente produzidos. Desse modo, percebem-se esforços no sentido de uma visão ampliada de saúde, articulando-a com a de doença. Mobiliza-se aqui, entre outros aspectos, o controle político sobre as pessoas e a extensividade da cobertura de diretrizes estabelecidas, sobretudo no que concerne a populações de baixa renda e suas condições restritivas de vida, dentre elas as de ordem sanitária.

Pois bem, sob outra perspectiva, os Estados Unidos, outro integrante do Grupo, entende que melhores serviços do setor podem ser oferecidos pela iniciativa privada[19]. Diante disso, cuidados médicos só podem ser obtidos mediante pagamento de seguros.

Outros países chamam ainda a atenção seja pela quantidade de mortes ou pela forma de combate ao vírus. Dentre esses, temos, por exemplo, Espanha, Suécia, República Checa, Suíça, Dinamarca, Eslovênia, Áustria, Croácia e Portugal.

Ao se identificar os espaços geográficos mais afetados pela pandemia do Sars-Cov2, a grande maioria, ao menos por enquanto, faz parte dos países mais desenvolvidos 
do planeta. O que serve de alerta para o restante do mundo, que precisa acompanhar seus desdobramentos, em aspectos diversos, com muita atenção, como, por exemplo, o Brasil, que apresenta um ritmo bastante elevado de contágios e óbitos.

Entender porque o vírus se dissipou tão rapidamente por esses locais não é uma tarefa propriamente difícil; afinal, vivemos em um período no qual nunca se teve uma velocidade tão grande de circulação de pessoas e produtos. Distâncias que no início do século XX levavam-se semanas para serem percorridas, hoje podem ser feitas em poucas horas.

Diante disso, a dissipação do vírus tornou-se um problema a ser combatido, pondonos, talvez, na contramão da globalização vertiginosa atual. Em outros termos, é provável que estejamos diante da necessidade de reduzir a velocidade das coisas, sob o sentido de uma contradição imprevista. Nesse momento, a famosa cena de "Tempos Modernos", na qual o ator Charlie Chaplin interpreta um operário de fábrica, que trabalha numa esteira de produção seriada, em ritmo acelerado, parece reduzirse a um filme de ficção.

Diante dessa nova lógica, sob uma espécie de império da velocidade, uma grande nuvem de incerteza e situações imprevistas paira sobre o mundo. Várias são as suposições sobre os cenários "pós-pandemia". Abordaremos aqui algumas recorrentes nos meios de comunicação, bem como as dos autores desse estudo.

Entre as diferentes opiniões, há quem acredite no fortalecimento das interações sociais presenciais, interações essas enfraquecidas pelas plataformas de encontros virtuais. Outra linha de pensamento questiona a manutenção da lógica de consumismo exacerbado incentivado por empresas com poucas preocupações socioambientais. Segundo esses questionadores, tais práticas estão perto do fim e serão substituídas por outras, que levariam em consideração o equilíbrio do sistema como um todo.

Além dessas, na contramão dos que acreditam no retorno das relações interpessoais mais próximas, há quem defenda que o isolamento servirá como um catalisador das 
novas dinâmicas do século XXI, reforçando, portanto, a tendência do home office e aumentando o distanciamento social. Mantendo essa lógica, é possível que muitos seguimentos fechem seus pontos comerciais físicos e se dediquem, exclusivamente, às plataformas virtuais. Destaque-se que no campo da educação isso já é uma realidade de diversas instituições, principalmente privadas, mas não somente. Existe também uma grande preocupação quanto aos impactos na economia, tanto na escala global quanto local, envolvendo grande dose de descontentamento por parte, sobretudo, de trabalhadores.

Com exceção dos contatos físicos, já está sendo possível presenciar um pouco dos efeitos causados pela pandemia da COVID-19. Para tentar garantir o mínimo de funcionamento possível, muitas instituições, públicas e privadas, estão com vários setores operando de forma remota ou virtual. Outras, que não têm condições de fazêlo, podem optar - devido ao campo de atuação - pela redução da jornada de trabalho, ou então operar com número reduzido de funcionários, em sistema de revezamento, ou, até mesmo, pararem suas atividades definitivamente. Para minimizar os prejuízos causados pela paralisação, a maioria dos governantes se dispôs a prestar auxílios[20], tanto às empresas como aos trabalhadores informais.

Quanto às opiniões sobre o padrão de consumo, pode-se também acompanhar algumas de suas implicações. Não é novidade que as empresas descobriram na obsolescência programada a fórmula do "movimento perpétuo" do lucro. Essa racionalidade irracional acaba por encher o mundo de resíduos que, em grande parte, são descartados como se fosse lixo[21], aumentando os níveis de degradação ambiental do planeta. Com a atual paralisação, o ritmo do consumo de vários produtos diminuiu drasticamente, mas nem todos os efeitos dessa redução podem ser vistos num curto espaço de tempo; porém, alguns já surtiram efeito em menos de 60 dias. Dentre esses, destaca-se a diminuição de particulados, oriundos das indústrias, em suspensão na atmosfera, que interferem diretamente na sua qualidade. Isso se comprova com a repercussão de notícias, no início de abril, de que algumas cidades indianas, após décadas sob intensa poluição do ar, voltaram a enxergar as montanhas do Himalaia, distantes a centenas de quilômetros. 
Como já observado, nenhum evento se dá por si só sem que haja a convergência de várias ações. Do mesmo modo, as implicações de alguns eventos não se restringem, unicamente, ao entorno da sua origem, adquirindo, não raro, proporções de larga escala. Diante disso, especulações quanto ao futuro da economia para um mundo pós COVID-19 estão na ordem do dia, levando pesquisadores renomados a se debruçarem sobre o assunto. Dentre eles, o geógrafo David Harvey assinala o seguinte:

A grande questão é: quanto tempo isto vai durar? Pode ser mais de um ano e quanto mais tempo durar, mais desvalorização, inclusive da força de trabalho. Os níveis de desemprego subirão, seguramente, para níveis comparáveis aos da década de 1930, na ausência de intervenções estatais maciças que terão de ir contra o neoliberalismo[...] (HARVEY, 2020, p.22)

Conforme apontado pelo autor, os prejuízos tendem a aumentar progressivamente com a duração da pandemia, a qual, apesar de ser um evento global, terá consequências distintas nos lugares. Novamente, a lógica está mantida, os países desenvolvidos e detentores das grandes tecnologias certamente terão menores dificuldades de superar essa crise. No entanto, outras economias que dependem da exportação de commodities e recursos naturais, com certeza terão muito mais dificuldades. Nesse contexto, um país que merece algumas considerações é o Brasil.

Possuindo proporções continentais e população acima dos 200 milhões de pessoas, atualmente o Brasil tem mais de dez milhões de desempregados. Quanto ao sistema de saúde, diferente dos países anteriormente analisados, os brasileiros podem contar com o Sistema Único de Saúde (SUS) bancado pelo governo federal. Além disso, ainda resta a quem puder e quiser a opção dos planos particulares, que geralmente oferecem atendimentos mais ágeis. No entanto, apesar dos problemas de ordem estrutural e orçamentária, a organização do SUS é estudada por outras nações devido ao seu nível de complexidade e funcionalidade, fruto, em grande medida, das grandes proporções territoriais do país.

Não diferente do mundo, o Brasil também está sofrendo com a pandemia da COVID19, levando quase todos os estados a adotarem o isolamento social. Dentre os 
diversos fatores que preocupam o país, e que, em larga medida, favorece a disseminação da doença, está a discrepante diferença de distribuição de renda, se não o maior, um de nossos problemas mais graves. Dito de outro modo reverbera aqui o problema representado pela desigualdade, com sua correspondente espacialidade acentuadamente contraditória e injusta.

Essas diferenças saltam aos olhos, principalmente nos grandes centros, através de favelas e complexos bolsões de pobreza. Na paisagem urbana estas formas espaciais contrastam com a presença multiplicada de condomínios fechados, não raro luxuosos. Constituindo expressões socioespaciais contraditórias, elas se apresentam nos tempos atuais cada vez mais aproximadas geograficamente, imprimindo não apenas um novo aspecto à desigualdade, como também representam uma espécie de oposição territorial degradante.

Nas comunidades empobrecidas o distanciamento social é uma tarefa quase que impossível, tanto pela precariedade das construções e dos espaços de circulação, com muitas casas aglomeradas, quanto pelas colocações de seus moradores no mercado de trabalho, desempenhando, de modo geral, funções de baixa remuneração, com boa parte atuando na informalidade. O que não Ihes permite constituir reservas de capital para imprevistos maiores ou mesmo ao enfrentamento de situações de crise, pressionando-os a deslocamentos regulares à luta cotidiana pela sobrevivência.

Sob o peso das adversidades ambientais e sanitárias, as populações que se acotovelam nesses espaços sujeitam-se, permanentemente, a maiores riscos de contágios e transmissibilidade do vírus, potencializando o risco de mortes. Talvez estejamos mesmo pagando o preço da desigualdade, como bem apontou o renomado médico brasileiro Drauzio Varella (2020).

Seguramente, os impactos da COVID-19 na economia mundial, com efeitos ainda imprevistos, afetam sensivelmente a dinâmica da circulação das mercadorias, impondo grandes restrições à reprodução do capital e à acumulação. Some-se a isto o fato desta economia estar submetida a um "novo" ciclo de crise desde os anos 1970, 
que se desdobra sob uma feição neoliberal, assentada no capital financeiro. Este modelo tem dado evidências quanto à sua insuficiência no atendimento de demandas à reprodução social da maioria da população, com maior contundência em países periféricos, como é o caso do Brasil.

Nesse sentido, a pandemia do coronavírus representa, indubitavelmente, um agravante robusto de uma crise que já estava em curso, que potencializa as contradições do sistema e dos fundamentos dessa economia. A pandemia - com seus efeitos - estaria representando um princípio de desordem na estrutura atual da globalização, comprometendo mais agudamente a sua organização?

É plausível considerar que talvez estejamos mesmo vivendo um ponto de inflexão na economia mundial e em nossas sociedades, apontando talvez para uma espécie de retro-globalização ou, talvez, como salientou o geógrafo Milton Santos (2000), de "uma outra globalização", forjada de baixo para cima, sinalizando para certo recuo ou "amortecimento" tanto da política feita pelo Estado como da imposição de uma política comandada pelas empresas e, sobretudo, corporações.

A despeito disso, pode-se entrever que problemas como a desigualdade socioterritorial e a precarização das relações de trabalho - com seus efeitos deletérios em instâncias diversas da sociedade - se redimensionem como situações-limite ao funcionamento e à manutenção do modelo econômico-social hegemônico. Se antes da pandemia o recrudescimento de suas contradições já nos impunha uma vida cotidiana compressiva e destituída de maiores horizontes, envolvendo a profusão do medo e da insegurança, com suas correspondentes espacialidades, agora nos vemos diante de um aparente paradoxo. Ele se apresentaria com uma combinação entre a presença de um campo-cego, no sentido de um curto circuito de expectativas; e, ao mesmo tempo, de reinvenções socioespaciais do viver, envolvendo possibilidades a novas e mais desejáveis formas de se estar no mundo, e até de rupturas em relação a padrões existentes, influindo situações socioespaciais sob uma revalorização da escala local. 
Ademais, chame-se a atenção para o cenário econômico que se desenha no país, o qual, mesmo contando com a presença de um grande pólo industrial como o representado pelo estado de São Paulo, revela um incremento significativo da mineração e do agronegócio em sua economia já há algumas décadas. $\mathrm{E}$, assim como na crise dos anos 70-80 que se abateu no Brasil, o campo, uma vez mais, poderá desempenhar um papel bastante importante no enfrentamento econômico da crise atual sob o coronavírus. Segundo a Confederação da Agricultura e Pecuária do Brasil (CNA)[22] em 2019, o agronegócio representou 21,4\% do PIB brasileiro total, com uma grande parte das produções desse setor orientada ao mercado externo, principalmente aos Estados Unidos, China e alguns países da Europa.

ADAMI (2020)[23], por sua vez, assinala que em janeiro deste ano (2020) houve uma redução nas importações de produtos do agronegócio brasileiro, com leve recuperação nos dois meses posteriores, com as exportações do setor nesses três meses alcançando um montante de mais de $\mathrm{U} \$ 21$ bilhões, com a China respondendo por $34 \%$ do total.

Cabe ressaltar que o presente estudo não desconsidera as contradições desse setor no Brasil, tais como a concentração fundiária, o desmatamento ilegal para implantação de algumas atividades, uso descontrolado de agrotóxicos, etc., componentes estes que, ao lado de outros, colocam em risco o equilíbrio do sistema. Contudo, há de se reconhecer o grande peso do agronegócio em nossa balança comercial. E, sobretudo nestes tempos de aprofundamento da crise global, produzido pela pandemia, esse segmento poderá propiciar, entre outros aspectos, recursos importantes ao custeio de despesas do combate ao coronavírus. Tanto o segmento de serviços como o da indústria revelam retrações sensíveis, com o setor da agropecuária sendo o único a mostrar crescimento.

Considere-se, ainda, que o setor do agronegócio no Brasil conta com grande emprego da mecanização, envolvendo, de modo geral, baixa utilização de força de trabalho, apresentando-se em condições teoricamente mais favoráveis à sua continuidade $e$ manutenção. Num cenário de desaceleração econômica, e de aumento significativo dos gastos públicos com a pandemia, este segmento adquire relevância ainda maior 
ao país, embora não se perca de vista demandas urgentes em relação à melhoria do sistema educacional e de saúde públicos, bem como ciência e tecnologia, segmentos basilares à qualquer sociedade que aspire condições efetivas a um real desenvolvimento.

O geógrafo David Harvey (2020) chama-nos a atenção para impactos e prejuízos produzidos pela pandemia num cenário de maior duração, cujos efeitos econômicos já se mostram fora de controle, com rupturas sistêmicas nas cadeias de valor. No limite esse estado de coisas implica em retração da produção com rupturas em sua cadeia, desemprego e queda no consumo produtivo, apontando para um quadro recessivo de amplas proporções. As circunstâncias e o comportamento dessa crise redimensionada estão em estreita dependência das ações humanas. Eles se articulam tanto a condições ambientais favoráveis, como em espaços mais úmidos de produção alimentar intensiva, e também ao modo como os seres humanos interagem entre si em condições de adensamento populacional e grande mobilidade geográfica das pessoas.

No Brasil, os níveis de desemprego que já se mostravam elevados antes da pandemia, aumentam significativamente, envolvendo grande preocupação em relação ao problema, de como reinserir os grandes contingentes de desempregados no mercado de trabalho e em que condições. Junte-se a isso o fato de o país apresentar cifras igualmente expressivas de analfabetismo funcional, num contexto em que essa crise reafirma a tendência de uma tecnificação ainda maior da sociedade. Contradição ou mesmo situação paradoxal que impõe desafios e riscos ainda mais robustos à sustentação da economia e da reprodução social em diversos territórios, sobretudo na periferia do sistema-mundo, comparecendo o Brasil como um caso emblemático, haja vista suas enormes contradições e desigualdades.

\section{CONSIDERAÇÕES FINAIS}

Já observamos que essa situação em curso não nos permite obter entendimentos conclusivos sobre o mundo pós Sars-Cov-2, havendo, ademais, o risco de uma segunda onda da doença. 
Desde o surgimento da COVID-19, o mundo vem passando por uma aceleração de transformações; as quais, em verdade, já estavam em curso, tais como a ampliação do uso de tecnologias digitais de informação e comunicação na vida social, bem como certa tendência da escola perder o fetiche da presença, ao mesmo tempo em que demanda o aprofundamento da qualificação de sua força de trabalho. Do mesmo modo em que o homem exalta sua capacidade mediante ao rápido sequenciamento genético do coronavírus e de suas mutações, também expõe suas fragilidades no trato das consequências da contaminação.

Diferentes posturas de governantes são refletidas na forma em que cada país está sendo afetado pela doença. De maneira geral, países que tardaram em decretar o distanciamento social e que possuem importantes aeroportos internacionais são, de modo geral, aqueles que vêm apresentando maiores números de infectados ou mortos.

Se, por um lado, há quem acredite numa mudança radical do comportamento humano tanto no que diz respeito à emissão de poluição ou nas relações interpessoais, por outro, o tempo nos ensina que o homem nem sempre aprende com o passado. Afinal, como exposto neste estudo, esta não é a primeira vez que a humanidade enfrenta uma pandemia e muito provavelmente também não será a última.

Para aqueles que acreditam numa reestruturação das relações sociais, pautada em melhores condições de emprego, redução do consumismo e uma nova estrutura de mercado financeiro, com empresas mais preocupadas com o equilíbrio socioambiental, é possível que tais crenças sejam frustradas. O vírus não deverá desaparecer tão rápido, havendo sinalizações quanto à possibilidade desse vírus se tornar endêmico. Além do mais, se sua origem realmente estiver relacionada a uma arma biológica, é perfeitamente plausível considerar que elas continuarão a ser produzidas.

Para além disso, um risco preocupante que corremos na esteira do aumento da tecnificação nas relações sociais é o aprofundamento dos níveis de monitoramento e controle de nossas vidas, colocando-nos numa situação de baixa relevância ao 
transformar pessoas em algoritmos. Para o mundo dos negócios, por exemplo, importará somente as informações desejadas. Harari (2020) nos alerta para os perigos do uso indiscriminado do monitoramento dos smartphones pelos governos e outros setores da sociedade, possibilitando que em curto espaço de tempo se possa ter acesso remoto a vários dados clínicos das pessoas. Essa tecnologia, se não controlada, poderá nos inserir em uma realidade até então só possível em filmes de ficção científica.

David Harvey (2020) assinala que muito provavelmente o consumismo verificado no mundo não diminua, mas admite que os produtos e os meios de sua aquisição possam sofrer mudanças. Muitas empresas estão investindo maciçamente nas plataformas de venda online que necessitam de pouca força de trabalho para mantê-las em funcionamento. Se para muitos consumidores essas mudanças soam como evolução, para milhões de trabalhadores que dependem das estruturas físicas dessas empresas, isso poderia soar como as "trombetas do apocalipse".

Caberia questionar se governos que permitem uma ampla flexibilização da economia e terceirizam serviços essenciais à população, como saúde, segurança e educação, têm condições de manter a massa de excluídos até uma suposta adequação dos mesmos a um ambiente mais favorável. Dificilmente! Como sabemos, o capital tende a migrar, invariavelmente, para lugares que oferecem condições mais favoráveis ao lucro, deixando à própria sorte os ambientes menos afortunados.

Uma coisa é certa, a forma como o homem está se relacionando com a natureza, e com os seus, não se sustenta por muito tempo, fornecendo evidências diversas de esgotamento. Urge que essa condição seja repensada mais ampla e aprofundadamente, o que solicita um grande consenso entre os líderes mundiais de que o território dos países é o espaço de reprodução da vida, antes de todas as coisas.

Projetos ambiciosos e altamente custosos, tais como pesquisas astronômicas em torno de outros planetas, são colocados à frente de grandes problemas sociais, dentre os quais o da desigualdade socioespacial, que tanto se aprofunda com a pandemia 
do coronavírus, como nela encontra condições - fruto de histórica negligência política - a sua maior expansão.

Acreditamos como algo pouco provável a ocorrência de um quadro de mudanças radicais após essa pandemia. Não se trata, evidentemente, de uma generalização, pois se reconhece aqui ações e iniciativas de várias instituições governamentais, e outros órgãos sociais, ao equacionamento da pandemia e seus impactos. Entretanto, a pandemia desvela a necessidade premente de maiores investimentos, com a devida transparência e controle social, na área da saúde pública, especialmente, tornando sua cobertura universal pelos mais variados lugares e sociedades. O que demanda, ao mesmo tempo, maiores esforços governamentais ao amplo fabrico de remédios importantes à vida das pessoas, sobretudo a populações mais carentes.

A consecução desses propósitos solicita também a sua inserção na agenda de movimentos sociais. Ao lado da educação, ciência e tecnologia, o segmento da saúde precisa ser alçado, no escopo das políticas governamentais, à condição de questão estratégica. Sob os efeitos da pandemia da COVID-19, a globalização contemporânea parece mesmo sinalizar a um ponto de inflexão na sua sustentação.

Para além das contradições econômicas do capitalismo e suas implicações restritivas, a condição atual expõe, com enorme contundência, a urgência quanto ao desenvolvimento de um complexo logístico de saúde pública no mundo, capaz de operar sistêmica e colaborativamente entre os países, devotado ao enfrentamento de pandemias e doenças de amplo espectro. Portanto, trata-se de um enorme desafio ao redimensionamento da relação entre política e ciência, de uma ciência que, definitivamente, se oriente bem mais e melhor à promoção da vida.

Diante do complexo cenário socioeconômico e socioambiental que envolve a pandemia e a crise a ela vinculada, impõe-se à Geografia a importante tarefa de apresentar à sociedade, de forma sistêmica, que essa situação não é um mero acaso das circunstâncias. Mas, essencialmente, um produto das ações humanas sob a lógica de realização e sustentação da sociedade contemporânea, que, reiteradamente, emite sinais e nos fornece evidências de seu equívoco biológico, 
resultado do metabolismo das ações humanas com a natureza; natureza essa entendida em seu sentido mais amplo, isto é, como algo inseparável da cultura, da economia, da política e da vida cotidiana.

Nessa perspectiva, a pandemia da COVID-19 reforça a importância dos geógrafos, ao lado de outros profissionais, no estudo de situações e possibilidades à construção de modos socialmente mais desejáveis e saudáveis de ser e estar no mundo. Do mesmo modo, também sinaliza a uma maior e mais efetiva articulação entre os variados segmentos que compõem a própria ciência geográfica, conferindo em seu escopo maiores preocupações em relação a questões de saúde pública nos espaços geográficos.

Não é demais lembrar que o planeta em que habitamos e vivemos se revela como algo complexo e interdependente, se modificando em ritmos nunca antes experimentados, que avança, entre outros aspectos, com a emergência de novos modos de organização societária e relacional. Nesse sentido, a pandemia parece estar suscitando potencialidades sistêmicas a certa reinvenção da vida cotidiana, estabelecendo novos contingenciamentos à experiência socioespacial, potencializando a percepção de um futuro em aberto e imprevisto. Mais do que ontem, a urdidura situacional da pandemia evidencia a necessidade - e talvez a urgência - de uma valorização radical da vida, reiteradamente antes de todas as coisas.

\section{REFERÊNCIAS}

ABRANCHES, Sergio. A era do imprevisto: a grande transição do século XXI. São Paulo: Companhia das Letras, 2017.

ADAMI, Andreia de Oliveira. Exportações do agronegócio brasileiro em meio à pandemia do coronavírus. CEPEA, 2020. Disponível em: https://www.cepea.esalq.usp.br/br/opiniao-cepea/exportacoes-do-agronegociobrasileiro-em-meio-a-pandemia-do-coronavirus.aspx. Acesso em 08 de maio de 2020. 
ALDAMA, Zigor. Megalomania chinesa: as obras públicas mais impactantes do país e sua baixa rentabilidade. El Pais. Xangai, 04, Jan. 2020. Disponível em: https://brasil.elpais.com/internacional/2020-01-04/megalomania-chinesa-as-obraspublicas-mais-impactantes-do-pais-e-sua-baixa-rentabilidade.html. Acesso em 20 de março de 2020.

BRASIL. Ministério da Saúde. Sobre a doença. Brasília, DF: 2020. Disponível em: < https://coronavirus.saude.gov.br/sobre-a-doenca >. Acesso em 18 de março de 2020.

CAPRA, Fritjof. O ponto de mutação. São Paulo: Cultrix, 1990.447p.

CHESNAIS, Fraçois. A mundialização do capital. São Paulo: Xamã, 1996.

DESJARDINS, Jeff. Mapped: The Median Age of the Population on Every Continent. Visual Capitalist. Vancouver, 2019. Disponível em: https://www.idealista.pt/news/financas/economia/2019/02/28/38924-idade-media-dapopulacao-por-continente-mais-jovens-estao-em-africa. Acesso em 25 de abril de 2020.

ESCOBAR, Pepe. 1 Video. Especial Pepe Escobar: a pandemia e a guerra EUAChina. Publicado pelo canal TV 247, 2020. Disponível em: https://www.youtube.com/watch?v=hu3_kQdwrxs. Acesso em 25 de março de 2020.

HARARI, Yuval Noah. O mundo após o coronavírus. Londres, 2020. Disponível em: https://www.ft.com/content/19d90308-6858-11ea-a3c9-1fe6fedcca75. Acesso em 21 de março de 2020.

HERRERA, Rémy; LONG, Zhiming. O Enigma do Crescimento Chinês. Revista Pesquisa e Debate, v. 29, n. 1(53), p. 8-22, 2018.

HARVEY, David. Condição pós-moderna. São Paulo: Edições Loyola, 1992.

El "nuevo" imperialismo: acumulación por desposesión. Buenos Aires: CLACSO, 2005. 
. Política anticapitalista en la época de COVID-19. In :DAVIS, Mike, et al: Coronavírus e a luta de classes. Terra sem Amos: Brasil, 2020. 48p.

ITÁLIA entra na nova Rota da Seda. DW, Bonn, 23, Mar. 2019. Disponível em: https://www.dw.com/pt-br/it\%C3\%A1lia-entra-na-nova-rota-da-seda/a-48039094.

Acesso em 02 de abril de 2020.

JESUS. Sara Carolina Rocha Pereira. Síndrome Respiratória do Médio Oriente. 2016. Disertação (Mestrado em Medicina) - Faculdade de Medicina de Lisboa, Universidade de Lisboa, Lisboa, 2016. Disponível em: https://repositorio.ul.pt/bitstream/10451/29480/1/SaraCJesus.pdf. Acesso em 20 de março de 2020.

LANDIM, Raquel. Preço de respiradores sobe mais de $200 \%$ na China em uma semana. CNN Brasil, 2020. Dispinível em https://www.cnnbrasil.com.br/business/2020/04/07/preco-de-respiradores-sobe-maisde-200-na-china-em-uma-semana. Acesso em 29 de maio de 2020.

ORGANIZAÇÃO DAS NAÇÕES UNIDAS (ONU). Department of Economic and Social Affairs. Population Division. World Population Prospects. 2019. New York. 39 p. Disponível

em: https://www.un.org/development/desa/pd/sites/www.un.org.development.desa.pd/file s/files/documents/2020/Jan/wpp2019_highlights.pdf. Acesso em 16 de abril de 2020.

Human Development Report. Beyond income, beyond averages, beyond today: Inequalities in human development in the 21st century. 2019. New York. 40 p. Disponível em: http://hdr.undp.org/sites/default/files/hdr_2019_overview__engidhlish.pdf. Acesso em 16 de abril de 2020.

ORGANIZAÇÃO MUNDIAL DE SAÚDE. O trabalho da OMS: relatório anual do Diretor-Geral à Assembléia Mundial da Saúde e às Nações Unidas. OMS, 1959. Disponível em: https://apps.who.int/iris/handle/10665/85722. Acesso em 01 de abril de 2020. 
ORGANIZAÇÃO PAN-AMERICANA DE SAÚDE. Doenças ocasionadas por vírus respiratórios emergentes, incluindo o COVID-19. Washington, 2020. Disponível em: https://www.campusvirtualsp.org/pt-br/curso/virus-respiratorios-emergentesincluindo-o-covid-19. Acesso em 18 de março de 2020.

PIB DO AGRONEGÓCIO CRESCE 3,81\% EM 2019. CNA, 2020. Disponível em: https://www.cnabrasil.org.br/boletins/pib-do-agronegocio-cresce-3-81-em-2019. Acesso em 08 de maio de 2020.

PIKETTY, Thomas. O capital no século XXI. Rio de Janeiro: Intrínseca, 2014.

SAAVEDRA,Ramon da Costa; DIAS, Juarez Pereira. Infecção por Yersinia pestis, no Estado da Bahia: controle efetivo ou silêncio epidemiológico?. Rev. Soc. Bras. Med. Trop. vol.44 no.2 Uberaba Mar./Apr. 2011, Epub Apr 01, 2011. Disponível em: https://www.scielo.br/pdf/rsbmt/v44n2/aop06-11.pdf. Acesso em: 23 de maio de 2020.

SANTOS, Milton. A urbanização brasileira. São Paulo: Hucitec, 1993.

Por uma outra globalização: do pensamento único à consciência universal. Rio de Janeiro: Record, 2000.

A natureza do espaço. $4^{\circ}$ ed. São Paulo: EDUSP, 2006.

SANTOS, Milton; SILVEIRA, María Laura. O Brasil: território e sociedade no século XXI. Rio e Janeiro: Record, 2001.

VARELLA, Antônio Drauzio. 1 Vídeo. Brasil Tem Estrutura Para Enfrentar Uma Pandemia? Especialistas Debatem. Publicado pelo canal UOL, 2020. Acesso em 07 de maio de 2020.

WHO. Word Health Organization. Middle East respiratory syndrome coronavirus (MERS-CoV). Genebra. 2020. Disponível em: https://www.who.int/es/news-room/factsheets/detail/middle-east-respiratory-syndrome-coronavirus-(mers-cov). Acesso em 18 de março de 2020. 


\section{APÊNDICE - REFERÊNCIAS DE NOTA DE RODAPÉ}

3. Para Milton Santos o espaço geográfico é constituído pelo conjunto indissociável de sistemas de objetos e sistemas de ações. Desse modo, à medida que o homem atua sobre o espaço ele o modifica ao passo que também é modificado. Por isso a indissociabilidade (SANTOS, 2006).

4. De acordo com Santos: "Por território entende-se geralmente a extensão apropriada e usada", sendo que ele, "num sentido mais restrito", constituiu "um nome político para o espaço de um país" (SANTOS, 2001, p.19).

5. Milton Santos apresenta o entendimento de que o "meio técnico-científicoinformacional" é a expressão geográfica da globalização contemporânea, mostrandose "marcado pela presença da ciência e da técnica nos processos de remodelação do território essenciais às produções hegemônicas, que necessitam desse novo meio geográfico para sua realização. A informação, em todas as suas formas, é o motor fundamental do processo social e o território é, também, equipado para facilitar a sua circulação" (SANTOS, 1993, p.35-36).

6. Sabe-se que o calendário moderno, no qual os anos são contabilizados por ciclos entre 365 e 366 dias, subdivididos em estações, está baseado em condições reais relativas à dinâmica do planeta, constituindo-se, ainda, num artifício humano para a classificação do tempo.

7. Em grego $[$ pan $=$ tudo/todo(s) $]$ e [demos $=$ povo]. Pandemia é quando uma doença infecciosa se dissemina para amplos espaços geográficos podendo alcançar proporções globais.

8. A doença também ficou conhecida popularmente como "febre do rato" ou "doença do rato".

9. O nome foi dado devido ao seu local de origem (Oriente Médio) ficando conhecido como Síndrome Respiratória do Oriente Médio (MERS). 
10. Transmitida do animal para o homem.

11. Os dromedários são do gênero Camelus dromedarius e são da mesma família dos camelos no entanto se diferem por alguns aspectos como resistência ao calor, capacidade de carga, velocidade de deslocamento, altura, etc. Nesses quesitos os dromedários são superiores aos camelos sendo largamente utilizado principalmente por povos de desertos. Outras diferenças são o número de corcovas e o habitat, nas quais os camelos possuem duas e são da Ásia Central enquanto os dromedários possuem apenas uma e se espalham pela Ásia também são encontrados na África. Ambos são essenciais para as populações tradicionais no desempenho de variadas atividade, isso explica, de certo modo, sua distribuição espacial e quantidade.

12. Países com relatos de casos de MERS: Alemanha, Arábia Saudita, Argélia, Áustria, Bahrein, China, Egito, Emirados Árabes Unidos, Estados Unidos da América, Filipinas, França, Grécia, Itália, Jordânia, Kuwait, Líbano, Malásia, Omã, Holanda, Catar, Reino Unido, República da Coréia, República Islâmica do Irã, Tailândia, Tunísia, Turquia e lêmen (OMS, 2020).

13. Registre-se que a China é o maior produtor mundial de respiradores, ventiladores e peças de reposição ao tratamento de doenças respiratórias (LANDIM, 2020).

14. Nesse caso, compreendem todos os equipamentos, ferramentas, instalações industriais, máquinas, porém não inclui os edifícios residenciais e nem o valor das suas terras.

15. Eram rotas milenares utilizadas por povos migratórios e comerciantes. No entanto recebeu esse nome devido a comercialização da seda entre a Europa e o oriente. Dentre as cidades europeias antigas Veneza na Itália, em função de sua espacialização e, também, tradição naval, desempenhou um importante papel na redistribuição dessas mercadorias para boa parte da Europa central. Inicialmente as mercadorias eram transportadas por animais de cargas nas rotas terrestres e barcos a velas nas rotas marítimas. Por sua importância simbólica na ligação entre o Ocidente e o Oriente, a China, em 2013, numa releitura dessa rota, lança o projeto "Belt and 
Road Initiative" (Iniciativa do Cinturão e Rota), que objetiva reforçar as ligações comerciais com o restante do mundo, investindo altas quantias de dinheiro em estradas, portos, ferrovias, aeroportos (em dezenas de países) e redes de telecomunicações. Diante disso, segundo o jornal alemão Deutsche Welle -DW(2019), em março de 2019 a Itália firmou um acordo com a China, se tornando o primeiro país do seleto grupo do G7 a aderir ao negócio.

16. Dentre várias obras desenvolvidas pelos chineses - que podem ser consideradas genuínas formas geográficas -, merece destaque a ponte "Hong Kong-Zhuhai-Macau", a mais longa do mundo sobre mares $(55 \mathrm{~km})$ e o aeroporto internacional de Pequim (Daxing), o maior do planeta, com seus setecentos mil metros quadrados (ALDAMA, 2020). Outro construto que não pode ser esquecido é a milenar Grande Muralha, com mais de 8 mil quilômetros de comprimento.

17. Dentre os eventos resgatados por Harari (2020) estão: Peste Negra, Varíola, AIDS e Ebola.

18. Entre os países africanos com melhores IDHs estão: Seicheles, Maurícia, Argélia, Tunísia, Botswana, Líbia, África do Sul, Gabão e Egito (ONU, 2019).

19. Apesar do sistema americano de saúde ser privado, o governo possui ampla autonomia para intervenção no mesmo, tendo como objetivo uma espécie de regulação contra práticas abusivas nos preços dos serviços.

20. O Brasil, por exemplo, se dispôs a ajudar com os custos dos salários dos trabalhadores formais além de uma ajuda de custo de $\mathrm{R} \$ 600,00$ para os trabalhadores informais. Ambos os auxílios são para um período de até três meses e estima-se que os valore ultrapassem os duzentos bilhões de reais. Já na Alemanha o ministro das finanças Olaf Scholz, chegou a anunciar que não haveria limites para ajudar as empresas, mas é possível que os valores gastos entre empresas e trabalhadores formais cheguem a cifras do trilhão de euros. 
21. De forma simples, é considerado lixo tudo aquilo que não tem mais utilidade. Já o resíduo se diferencia desse por ainda permitir algum tipo de reutilização seja na forma que se encontra ou como matéria prima para outros produtos.

22. O estudo foi realizado pelo Centro de Estudos Avançados em Economia Aplicada (CEPEA), da Esalq/USP, em parceria com a Confederação da Agricultura e Pecuária do Brasil (CNA) e com a Fundação de Estudos Agrários Luiz de Queiroz (Fealq).

23. Andreia de Oliveira Adami é pesquisadora da área de Macroeconomia do Centro de Estudos Avançados em Economia Aplicada (CEPEA).

Enviado: Junho, 2020.

Aprovado: Julho, 2020. 